\title{
Casca de soja em dietas para coelhos em crescimento
}

\author{
Soybean hulls on diets for growing rabbits
}

\author{
Ana Carolina Kohlrausch Klinger ${ }^{I^{*}}$ Geni Salete Pinto de Toledo ${ }^{\text {II }}$ Daniel Prois Eggers ${ }^{\mathrm{I}}$ \\ Alexandra Pretto ${ }^{\mathrm{I}}$ Michael Chimainski ${ }^{\text {III }}$ Leila Picolli da Silva ${ }^{\text {II }}$
}

\section{RESUMO}

O presente trabalho teve como objetivo avaliar efeitos da inclusão de casca de soja em substituição ao feno de alfafa sobre o desempenho, características da carcaça e trato gastrointestinal e parâmetros bioquímicos de coelhos em fase de crescimento. Foram utilizados 30 coelhos da raça Nova Zelândia Branca, divididos igualmente em três tratamentos, compostos pela dieta experimental padrão (sem inclusão de casca de soja); e pelas dietas com $50 \%$ e $100 \%$ de substituição de alfafa por casca de soja nas respectivas rações experimentais. Concluiu-se que a casca de soja pode ser incluída em dietas para coelhos em crescimento, em substituição ao feno de alfafa em até $100 \%$ sem causar danos no desempenho nas características de carcaça e do trato gastrointestinal e parâmetros bioquímicos dos animais, durante a fase de crescimento. Porém, a utilização deste co-produto exige a necessidade de estudos mais aprofundados em virtude da escassez de dados.

Palavras-chave: casquinha de soja, co-produtos, cunicultura.

\section{ABSTRACT}

This study aimed to evaluate the effects of inclusion of soybean hulls in the replacement of alfalfa hay on performance, of growing rabbits. A total of 30 rabbits of New Zealand White kind were divided into three treatments, experimental compounds in the pattern diet (without inclusion of soybean hulls), and the diets with $50 \%$ and $100 \%$ replacement of alfalfa by soybean hulls in their experimental diets. It was concluded that the soybean hulls can be included on replace of alfafa hulls up 100\% in rabbits diets. However, the use of coproduct in animal nutrition need more detailed studies because of the paucity of data.

Key words: byproducts, cuniculture, soybean hulls.

\section{INTRODUÇÃO}

As atividades agropecuárias competem por alguns cereais e fontes proteicas vegetais convencionais com a nutrição humana. Neste ponto de vista, a cunicultura apresenta vantagens sobre a produção dos demais monogástricos. $\mathrm{O}$ coelho, pelo fato de apresentar o ceco funcional e praticar a cecotrofia apresenta capacidade de se alimentar com considerável quantidade de produtos fibrosos, extraindo nutrientes advindos de alimentos não convencionais e transformando-os em carne de alto valor biológico para a nutrição humana (FIGUEIRA, 2009). O feno de alfafa é considerado uma fonte balanceada de fibra, capaz de suprir as exigências nutricionais do coelho ao ser incluído em torno de $30 \%$ na dieta, porém, devido ao seu alto valor comercial, onera em até $40 \%$ o custo da dieta (SCAPINELLO et al., 2006).

Nesse contexto, esforços científicos têm sido concentrados na busca por alimentos alternativos ao feno de alfafa, sendo que grande variedade de co-produtos oriundos do processamento de fontes vegetais (oleaginosas e cereais) estão disponíveis no mercado sob a forma de tortas e farelos (RETORE et al., 2010). Assim, por se tratar de um co-produto rico em fibras ( $45 \%$ de fibra em detergente ácido), com cerca de $13 \%$ de proteína bruta (GENTILINI \& LIMA, 1996), a casca de soja emerge como uma fonte alternativa promissora na alimentação de coelhos.

\footnotetext{
'Curso de Pós-graduação em Produção Animal, Departamento de Zootecnia, Universidade Federal de Santa Maria (UFSM), Av. Roraima, 1000, 97105-900, Santa Maria, RS, Brasil. E-mail: aninhaklinger@zootecnista.com.br. *Autor para correspondência.

"Departamento de Zootecnia, Centro de Ciências Rurais (CCR), UFSM, Santa Maria, RS, Brasil.

IIICurso de Zootecnia, UFSM, Santa Maria, RS, Brasil.
} 
A casca de soja é definida como um coproduto oriundo do processamento da soja que representa 7 a $8 \%$ do peso do grão. De acordo com os dados da CONAB, a safra brasileira em 2011/2012 gerou cerca de 66 milhões de toneladas desta leguminosa, e consequentemente em torno de cinco milhões de toneladas de casca. Neste viés, a inclusão de fontes alternativas em substituição ao feno de alfafa, além de ser biologicamente viável, figura também como um fator redutor dos custos envolvidos na dieta.

Pesquisas abrangendo a utilização de co-produtos na nutrição animal são vastas, porém dados com coelhos são escassos, havendo assim a necessidade de estudos mais aprofundados com a espécie. Diante desses aspectos, o objetivo deste estudo foi verificar o desempenho, as características de carcaça e do trato gastrointestinal e parâmetros bioquímicos de coelhos da raça Nova Zelândia durante a fase de crescimento, alimentados com dietas contendo casca de soja em substituição ao feno de alfafa.

\section{MATERIAL E MÉTODOS}

O ensaio biológico foi conduzido entre os meses de outubro e dezembro de 2012. Foram utilizados 30 coelhos da raça Nova Zelândia Branco, de ambos os sexos, desmamados aos 35 dias de idade, previamente uniformizados com base no peso vivo e distribuídos aleatoriamente nos tratamentos. Os animais foram alojados individualmente em gaiolas de cimento pré-moldado, frente e piso de arame galvanizado, e equipadas com comedouros e bebedouros de cerâmica.

Inicialmente, os animais passaram por uma adaptação às dietas experimentais durante cinco dias e, posteriormente, receberam os tratamentos: T0CS = dieta sem inclusão de casca de soja; T50CS = substituição de $50 \%$ do feno de alfafa por casca de soja; T100CS = substituição de $100 \%$ do feno de alfafa por casca de soja (Tabela 1). As dietas foram isonutritivas e formuladas para atender as necessidades da categoria correspondente. As rações foram confeccionadas na Fábrica de Rações do DZ/UFSM, na forma física

Tabela 1 - Formulação das dietas experimentais (\%).

\begin{tabular}{|c|c|c|c|}
\hline \multirow[t]{2}{*}{ Ingredientes } & \multicolumn{3}{|c|}{-Tratamentos----- } \\
\hline & TOCS & T50CS & T100CS \\
\hline Milho & 17,25 & 17,60 & 17,60 \\
\hline Casca de arroz & 6,00 & 5,02 & 4,72 \\
\hline Farelo de trigo & 25,00 & 25,00 & 25,00 \\
\hline Feno de alfafa & 30,00 & 15,00 & 0,00 \\
\hline Farelo de soja & 17,50 & 20,90 & 24,30 \\
\hline Óleo de soja & 2,500 & 2,80 & 3,70 \\
\hline Casca do grão de soja & 0,00 & 11,00 & 22,00 \\
\hline Sal & 0,50 & 0,50 & 0,50 \\
\hline Fosfato bicálcico & 0,81 & 1,00 & 1,00 \\
\hline Calcário calcítico & 0,24 & 0,98 & 0,98 \\
\hline Premix vitamínico e mineral ${ }^{1}$ & 0,20 & 0,20 & 0,20 \\
\hline Total & 100,00 & 100,00 & 100,00 \\
\hline \multicolumn{4}{|l|}{ Nutrientes } \\
\hline Proteína bruta (\%) & 18,00 & 18,00 & 18,00 \\
\hline Extrato etéreo (\%) & 3,00 & 3,00 & 3,00 \\
\hline FDA $(\%)$ & 15,00 & 15,00 & 15,00 \\
\hline Cálcio $(\%)$ & 0,84 & 0,84 & 0,84 \\
\hline Fósforo útil (\%) & 0,45 & 0,45 & 0,45 \\
\hline Fósforo total (\%) & 0,70 & 0,70 & 0,70 \\
\hline Energia digestível $\left(\mathrm{Kcal} \mathrm{kg}^{-1}\right)$ & 2600,00 & 2600,00 & 2600,00 \\
\hline Lisina total $(\%)$ & 0,70 & 0,70 & 0,70 \\
\hline Sódio $(\%)$ & 0,23 & 0,23 & 0,23 \\
\hline
\end{tabular}

Sendo: T0CS, T50CS, e T100CS tratamentos com 0\%, 50\% e 100\% de inclusão de casca de soja em substituição ao feno de alfafa.

Composição da casca de soja $(\%)$ : proteína bruta=10,65; gordura=1,14; fibra em detergente ácido $(\mathrm{FDA})=50,36$; hemiceluloses=20,42; celulose $=47,78$; ligninas $=5,26$; fibra solúvel $=17,09$.

Ciência Rural, v.45, n.1, jan, 2015. 
farelada, sendo as análises bromatológicas realizadas de acordo com a AOAC (1995).

Os animais receberam água e ração à vontade e a quantidade de ração foi aferida a cada 15 dias, determinando assim o consumo. Após 44 dias de alimentação, todos os animais foram pesados e cinco animais de cada tratamento foram anestesiados para coleta de sangue através de punção cardíaca após aplicação intramuscular do anestésico diazepam (2mg kg-1) (TABORDA et al., 2004). Após a coleta de sangue, os coelhos foram abatidos por sangria na jugular, procedendo assim à retirada da pele, evisceração completa, pesagem da carcaça e órgãos. Os parâmetros avaliados foram: peso vivo final (PVF), ganho médio diário (GMD), consumo diário de ração (CDR), conversão alimentar (CA), pesos do estômago vazio (PEV), intestino vazio (PIV) e ceco vazio (PCV), peso da carcaça quente (PCQ) e rendimento da carcaça quente (RCQ). Foram amostrados também parte do trato digestivo dos coelhos (jejuno) para verificar a atividade de enzimas digestivas e fígado, para análise de glicogênio e amino transferases hepáticas.

Em seguida, as carcaças foram guardadas individualmente em embalagens plásticas e armazenadas em freezer a $-18^{\circ} \mathrm{C}$ até o preparo das amostras para a análise de composição centesimal. As carcaças foram moídas em moedor de carnes elétrico e após finamente trituradas em processador de alimentos. Das amostras totais homogeneizadas, foram retiradas subamostras $( \pm 200 \mathrm{~g})$ para análise de matéria seca, matéria mineral e proteína bruta (SILVA, 1990) e gordura (BLIGH \& DYER, 1959). Para verificar o efeito da inclusão de casca de soja sobre características visuais da carne, foi conduzida a avaliação instrumental da cor, em uma amostra de carne (músculo Longíssimos dorsi) de cada unidade experimental, utilizando colorímetro MINOLTA CR-300 com um sistema de iluminação padrão D65, com $10^{\circ}$ de ângulo de observação. Foram medidos os valores de L (luminosidade), +a (tendência ao vermelho) $\mathrm{e}+\mathrm{b}$ (tendência ao azul), seguindo o espaço de cores "CIE 1976 L*a*b".

As amostras de sangue foram centrifugadas a $1000 \mathrm{~g}$ durante $10 \mathrm{~min}$ para obtenção de soro e posterior quantificação de albumina (método do biureto), proteínas totais $\left(\mathrm{g} \mathrm{dL}^{-1}\right)$ (método de verde bromocresol) e triglicerídeos $\left(\mathrm{mg} \mathrm{dL}^{-1}\right)$ (método enzimático), utilizando-se kits colorimétricos comerciais Doles (Goiânia, GO-Brasil). Nas amostras de jejuno, foi descartado o conteúdo intestinal e o órgão foi seccionado para obter uma subamostra $( \pm 0,5 \mathrm{~g})$. As subamostras foram homogeneizadas (proporção tecido:tampão homogeneização 1:20) em banho de gelo com homogeneizador tipo Turrax (modelo MS 102, Marconi). O tampão era composto por Tris $0,02 \mathrm{M}$ e fosfato de sódio $0,01 \mathrm{M}$ em $50 \%$ (v/v) de glicerol em $\mathrm{pH} 7,0$. Os homogeneizados foram centrifugados a $1200 \mathrm{~g}$ durante $10 \mathrm{~min}$ e os sobrenadantes (homogeneizados brutos) foram utilizados como fonte de enzima para os ensaios da atividade de enzimas digestivas.

A atividade de amilase foi ensaiada

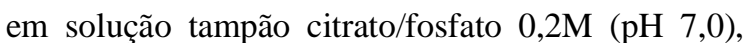
contendo $\mathrm{NaCl}$ 0,02M, com solução de amido 2,5\% como substrato. A reação foi incubada a $25^{\circ} \mathrm{C}$ durante 40 min, interrompida com $\mathrm{ZnSO}_{4} 5 \%$ e $\mathrm{Ba}(\mathrm{OH})_{2} 0,3 \mathrm{~N}$ e centrifugada a $1200 \mathrm{~g}$ durante $3 \mathrm{~min}$. A glicose livre foi determinada segundo PARK \& JOHNSON (1949) a $660 \mathrm{~nm}$. A atividade específica foi expressa como $\mu \mathrm{mol}$ glicose $/ \mathrm{min} / \mathrm{mg}$ proteína. As enzimas tripsina e quimotripsina foram ensaiadas conforme HUMMEL (1959). Para tripsina, foi utilizada solução tampão $\mathrm{CaCl}_{2}$ 0,01M e Tris- $\mathrm{HCl}$ 0,2M (pH 8,1) com 1,04mM de TAME diluído em solução tampão como substrato ( $\alpha$ - $p$-toluene-sulfonyl- $L$-argininemethylesterhydroch loride). A reação foi incubada a $25^{\circ} \mathrm{C}$ e a absorvância verificada em $247 \mathrm{~nm}$ durante $60 \mathrm{~s}$. O substrato utilizado para a quimiotripsina foi $1 \mathrm{mM}$ BTEE ( $N$-benzoyl-Ltyrosineethylester) em metanol 2:3 (v/v), ensaiada em $\mathrm{CaCl}_{2} 0,1 \mathrm{M}$ e Tris- $\mathrm{HCl} 0,1 \mathrm{M}(\mathrm{pH}$ $7,8)$ a $25^{\circ} \mathrm{C}$, durante $60 \mathrm{~s}$ a $256 \mathrm{~nm}$. Atividades foram expressas como $\mu \mathrm{mol}$ de arginina/min/mg proteína e $\mu \mathrm{mol}$ de tirosina/min/mg proteína, respectivamente. A fim de obter a atividade específica das enzimas, a concentração de proteína foi determinada no extrato enzimático pelo método de BRADFORD (1976), usando albumina bovina como padrão.

Para extração do glicogênio hepático, amostras de fígado $(50 \mathrm{mg})$ foram adicionadas à solução de $\mathrm{KOH} 6 \mathrm{~N}$ (1mL) em banho-maria a $100^{\circ} \mathrm{C}$. Após, o metabólito foi precipitado em etanol e solubilizado em água destilada $(2,5 \mathrm{~mL})$. O teor de glicogênio (mg $100 \mathrm{~g}^{-1}$ fígado) foi determinado através da cor produzida pela reação do glicogênio com o iodo, utilizando como padrão glicogênio bovino, de acordo com KRISMAN (1962). A fim de analisaras transaminases hepáticas, amostras de fígado foram homogeneizadas com solução tampão fosfato de potássio 0,02M pH 7,5 (proporção peso:volume 1:20) em banho de gelo. A seguir, os extratos foram centrifugados a $1200 \mathrm{~g}$ durante 10 mine mantidos sob refrigeração $\left(-18^{\circ} \mathrm{C}\right)$ até o momento das análises. Alanina amino transferase (ALT) e aspartato amino transferase (AST) foram quantificadas com o uso de kits colorimétricos Doles (Goiânia, GO-Brasil) após 
confecção da curva padrão (metodologia de Frankel Reitman). A concentração das transaminases foi expressa como UI de ALT ou AST mg-1 tecido.

O delineamento utilizado foi o inteiramente casualizado com três tratamentos e 12 repetições, sendo cada animal considerado uma unidade experimental. Dos resultados obtidos, foram retirados os valores anômalos (média $\pm 2 \mathrm{dp}$ ). Em seguida, os dados foram submetidos à análise de variância e as médias comparadas pelo teste de Duncan a 5\% de significância, com auxílio do Programa Estatístico SPSS 8.0.

\section{RESULTADOS E DISCUSSÃO}

Em relação ao desempenho, após 44 dias de alimentação, o tratamento T50CS resultou em maior PVF e melhor CA em relação aos animais que receberam o tratamento TOCS (controle), porém não diferindo do tratamento T100CS (Tabela 2). Também não foi verificada diferença entre os tratamentos T0CS e T100CS nos referidos parâmetros. Quanto ao GMD e CDR, não houve diferenças significativas entre os animais alimentados com as três diferentes dietas, assim como para os parâmetros gastrointestinais avaliados como PEV, PIV e PCV (Tabela 3). Nesse sentido, estes resultados discordam de ARRUDA et al. (2003), que afirmam que a fonte de fibra pode alterar o consumo dos animais. Ainda os referidos autores alegam que, em experimento com coelhos expostos a diferentes fontes de fibra na dieta, os animais alimentados com as rações a base de feno de alfafa consumiram mais que o grupo submetido a dietas com casca de soja. Em experimento similar com coelhos abatidos aos 89 dias de idade, submetidos ao nível de $10,6 \%$ de substituição do feno de alfafa por casca de soja, RETORE (2009) não encontrou diferenças significativas no desempenho dos animais. Neste aspecto, FIGUEIRA (2009) avaliou o desempenho de coelhos da raça Nova Zelândia Branco na fase de crescimento, submetidos a níveis de $0 \%, 50 \%, 75 \%$ e $100 \%$ de casca de soja em substituição do feno de alfafa presente na dieta. A referida autora cita que, excluindo a dieta testemunha, foi observado aumento linear no peso vivo ao abate, ganho de peso e consumo de ração no período de 32 a 70 dias de idade, com o aumento da inclusão de casca de soja moída.

Em relação aos parâmetros avaliados na carcaça, maior peso e rendimento foram observados nos animais alimentados com a dieta T100CS em relação ao tratamento T0CS. No entanto, estes resultados não diferem daqueles apresentados no tratamento T50CS. A análise da composição nutricional revelou menor teor de cinzas e mais gordura na carcaça dos animais alimentados com a dieta T50CS em comparação ao tratamento tido como padrão (T0CS). A dieta T100CS proporcionou teor de gordura semelhante ao tratamento TOCS. O teor de matéria seca e proteína bruta não diferiu entre os tratamentos em estudo. ARRUDA et al. (2003) verificaram que a substituição total de feno de alfafa por casca de soja não alterou o teor de matéria seca, gordura e proteína da carcaça de coelhos. A análise de coloração da carne não revelou diferenças para luminosidade e tendências ao vermelho ou azul, demonstrando que a inclusão de casca de soja na dieta de coelhos, até mesmo em substituição total ao feno de alfafa não altera características visuais deste produto ao consumidor.

Apesar das diferenças encontradas para o ganho de peso e composição da carcaça, os parâmetros séricos como albumina, triglicerídeos e proteínas totais não diferiram entre os tratamentos (Tabela 4). Da mesma forma, a atividade das enzimas amilase, tripsina e quimotripsina analisadas no intestino e a concentração das amino transferases (alanina e asparta toamino transferase) hepáticas não apresentaram diferenças significativas entre os animais alimentados

Tabela 2 - Medidas de desempenho de coelhos abatidos aos 79 dias de idade.

\begin{tabular}{|c|c|c|c|}
\hline Variáveis & TOCS & T50CS & T100CS \\
\hline PVI (g) & $579,60 \pm 50,00$ & $580,40 \pm 68,90$ & $580,90 \pm 65,30$ \\
\hline $\operatorname{PVF}(g)$ & $1886,70 \pm 164,00^{b}$ & $2047,90 \pm 201,50^{\mathrm{a}}$ & $2005,40 \pm 157,60^{\mathrm{ab}}$ \\
\hline GMD (g) & $29,71 \pm 2,95$ & $33,37 \pm 3,66$ & $32,38 \pm 4,36$ \\
\hline CDR $(g)$ & $0,93 \pm 10,85$ & $104,95 \pm 13,06$ & $102,17 \pm 16,82$ \\
\hline $\mathrm{CA}\left(\mathrm{kg} \mathrm{kg}^{-1}\right)$ & $3,13 \pm 0,31$ & $3,25 \pm 0,23$ & $3,05 \pm 0,29$ \\
\hline
\end{tabular}

Médias seguidas de letras diferentes na mesma linha diferem significativamente pelo teste de Duncan (P<0,05). Sendo: T0CS, T50CS, e T100CS tratamentos com $0 \%, 50 \%$ e $100 \%$ de inclusão de casca de soja em substituição ao feno de alfafa. PVI=peso vivo inicial; PVF=peso vivo final; $\mathrm{GMD}=$ ganho médio diário; $\mathrm{CDR}=$ consumo diário de ração; $\mathrm{CA}=$ conversão alimentar. 
Tabela 3 - Medidas de carcaça e trato gastrintestinal de coelhos abatidos aos 79 dias de idade.

\begin{tabular}{|c|c|c|c|}
\hline Variáveis & TOCS & T50CS & T100CS \\
\hline $\operatorname{PEV}(\mathrm{g})$ & $34,17 \pm 2,04$ & $36,67 \pm 6,83$ & $34,17 \pm 3,76$ \\
\hline PIV (g) & $93,00 \pm 8,37$ & $99,17 \pm 8,61$ & $92,50 \pm 11,29$ \\
\hline $\mathrm{PCV}(\mathrm{g})$ & $39,00 \pm 8,22$ & $44,17 \pm 7,36$ & $41,67 \pm 6,83$ \\
\hline PCQ (g) & $1060,00 \pm 51,80^{\mathrm{b}}$ & $1083,3 \pm 77,8^{\mathrm{ab}}$ & $1165,00 \pm 63,30^{\mathrm{a}}$ \\
\hline RCQ (\%) & $53,75 \pm 2,20^{\mathrm{b}}$ & $54,47 \pm 0,85^{\mathrm{ab}}$ & $56,04 \pm 1,21^{\mathrm{a}}$ \\
\hline Matériaseca (\%) & $30,96 \pm 1,20$ & $31,73 \pm 0,61$ & $31,35 \pm 2,35$ \\
\hline Matéria mineral (\%) & $4,02 \pm 0,68^{\mathrm{a}}$ & $3,30 \pm 0,54^{\mathrm{b}}$ & $3,85 \pm 0,61^{\mathrm{a}}$ \\
\hline Proteínabruta $(\%)$ & $19,08 \pm 0,97$ & $19,26 \pm 0,97$ & $19,35 \pm 0,77$ \\
\hline Gordura (\%) & $6,83 \pm 0,56^{\mathrm{b}}$ & $8,24 \pm 1,27^{\mathrm{a}}$ & $7,44 \pm 1,67^{\mathrm{ab}}$ \\
\hline $\mathrm{L}$ & $57,95 \pm 2,02$ & $57,48 \pm 1,71$ & $59,22 \pm 1,29$ \\
\hline Vermelho (+a) & $14,67 \pm 1,81$ & $16,61 \pm 1,59$ & $15,42 \pm 2,32$ \\
\hline azul $(+b)$ & $5,49 \pm 1,26$ & $6,03 \pm 1,03$ & $6,21 \pm 0,56$ \\
\hline
\end{tabular}

Médias seguidas de letras diferentes na mesma linha diferem significativamente pelo teste de Duncan (P<0,05). Sendo: T0CS, T50CS, e T100CS tratamentos com $0 \%, 50 \%$ e $100 \%$ de inclusão de casca de soja em substituição ao feno de alfafa. PEV=peso do estômago vazio; $\mathrm{PIV}=$ peso do intestino vazio; $\mathrm{PCV}=$ peso do ceco vazio; $\mathrm{PCQ}=$ peso da carcaça quente; $\mathrm{RCQ}=$ rendimento da carcaça quente; $\mathrm{L}=$ luminosidade.

com as dietas contendo casca de soja em comparação à dieta contendo feno de alfafa. RETORE et al. (2010) também observou semelhante concentração sérica de triglicerídeos em coelhos alimentados com dietas contendo feno de alfafa ou casca de soja, porém diferentemente dos resultados encontrados no presente estudo, os animais que receberam a dieta contendo casca de soja apresentaram mais proteína sérica circulante, possivelmente causado por desbalanceamento nutricional.

De acordo com Dojanã et al. (1998) a atividade de amilase é fortemente estimulada pelo contato digestivo com amido. Os referidos autores ainda observaram modificações na secreção de amilase e lipase de acordo com mudanças na composição do alimento, além de alterações na atividade de tripsina e quimotripsina sob ação de diferentes proteínas alimentares, podendo supor a adaptabilidade na secreção de enzimas pancreáticas no coelho, em resposta à composição da dieta (DOJANÃ et al., 1998).

Em resumo, os dados obtidos no presente estudo demonstram que a substituição total do feno de alfafa por casca de soja na alimentação de coelhos

Tabela 4- Parâmetros bioquímicos no soro, trato digestivo (jejuno) e fígado de coelhos abatidos aos 79 dias de idade.

\begin{tabular}{|c|c|c|c|}
\hline Variáveis & TOCS & T50CS & T100CS \\
\hline Albumina & $2,92 \pm 0,19$ & $3,00 \pm 0,15$ & $3,03 \pm 0,10$ \\
\hline Triglicerídeos & $135,00 \pm 53,51$ & $146,00 \pm 23,70$ & $100,00 \pm 42,30$ \\
\hline Proteínastotais & $5,58 \pm 0,48$ & $5,67 \pm 0,31$ & $5,91 \pm 0,34$ \\
\hline Amilase & $0,12 \pm 0,03$ & $0,12 \pm 0,03$ & $0,12 \pm 0,02$ \\
\hline Tripsina & $4,97 \pm 0,61$ & $4,95 \pm 0,17$ & $5,19 \pm 0,64$ \\
\hline Quimotripsina & $3109,00 \pm 375,42$ & $3243,00 \pm 217,66$ & $3240,00 \pm 316,46$ \\
\hline ALT & $553,00 \pm 70,64$ & $684,00 \pm 140,38$ & $681,00 \pm 213,13$ \\
\hline AST & $1387,00 \pm 221,84$ & $1279,00 \pm 192,80$ & $1487,00 \pm 287,50$ \\
\hline
\end{tabular}

Médias seguidas de letras diferentes na mesma linha diferem significativamente pelo teste de Duncan (P<0,05).Sendo: T0CS, T50CS, e T100CS tratamentos com $0 \%, 50 \%$ e $100 \%$ de inclusão de casca de soja em substituição ao feno de alfafa. ALT=alanina amino transferase; AST=aspartato amino transferase. 
proporciona satisfatório desempenho zootécnico aos animais, sem alterar parâmetros digestivos e comprometer características de carcaça.

\section{CONCLUSÃO}

A casca de soja pode ser incluída em dietas para coelhos em crescimento em substituição ao feno de alfafa, em até $100 \%$ durante a fase de crescimento. Os dados obtidos neste estudo podem colaborar para o crescimento da cunicultura, mas ainda são necessários estudos mais aprofundados com a utilização deste coproduto em virtude da escassez de dados.

\section{COMITÊ DE ÉTICA E BIOSSEGURANÇA}

Projeto aprovado, com parecer nํㅜ 098/2011.

\section{REFERÊNCIAS}

AOAC (ASSOCIATION OF OFFICIAL ANALYTICAL CHEMISTS). Official methods of analysis of the AOAC international. 16.ed. Washington, 1995. 1018p. (Supplement 1998).

ARRUDA, A.M.V. et al. Importância da fibra na nutrição de coelhos. Semina: Ciências Agrárias, Londrina, v.24, n.1, p.181190, 2003. Disponível em: <http://www.uel.br/revistas/uel/index. php/semagrarias/article/view/2153/1847>. Acesso em: 14 abr. 2013.

BLIGH, E.G.; DYER, W.J. A rapid method of total lipid extraction and purification. Canadian Journal of Biochemistry and Physiology, v.37, p.911-917, 1959. Disponível em: <http://www. nrcresearchpress.com/doi/abs/10.1139/o59099?journalCode=cjbp\#. UWtkhKLU-3k>. Acesso em: 14 abr. 2013.

BRADFORD, M.M.A. A rapid and sensitive method for the quantification of microgram quantities of protein utilizing the principle of protein-dye binding. Analytical Biochemistry, v.72, p.248-254, 1976.

CONAB. Acompanhamento da safra brasileira: grãos, primeiro levantamento. Brasília: Companhia Nacional de Abastecimento. 2012. Disponível em: <http://www.conab.gov.br/OlalaCMS/ uploads/arquivos/12_10_09_15_59_18_boletim_portugues outubro_2012.pdf>. Acesso em: 14 abr. 2013 .

DOJANĂ, N.M. et al. The activity of some digestive enzymes indomestic rabbits before and after weaning. Animal Science, v.66, n.02, p.501-507, 1998. Disponível em: <http://journals. cambridge.org/action/displayAbstract?fromPage $=$ online $\&$ a id=6950824>. Acesso em: 14 abr. 2013.
FIGUEIRA, J.L. Casca de soja na alimentação de coelhos em crescimento em substituição aos fenos de alfafa e coastcross. 2009. 37 p. Dissertação (Mestrado em Zootecnia) - Curso de PósGraduação em Zootecnia, Universidade Estadual de Maringá.

GENTILINI, F.P.; LIMA, G.J.M.M. Análise microscópica e determinação da atividade ureática dos componentes do subproduto casca de soja. Reunião Anual da Sociedade Brasileira de Zootecnia, v.33, p.260-262, 1996

HUMMEL, B.C.W. A modified spectrophotometric determination of chymotrypsin, trypsin and thrombin. Canadian Journal of Biochemistry and Physiology, v.37, n,12, p.1393-1399, 1959. Disponível em: <http://www.nrcresearchpress.com/doi/ abs/10.1139/o59-157? journalCode=cjbp\#.UWtpoKLU-3k> . Acesso em: 14 abr. 2013.

KRISMAN, C.R. A method for the colorimetric estimation of glycogen with iodine. Analytical Biochemistry, v.4, p.17-23, 1962. Disponível em: <http://ac.els-cdn. com/0003269762900143/1-s2.0-0003269762900143-main.pdf? tid $=957 \mathrm{fd} 8 \mathrm{~b} 6-26 \mathrm{af}-11 \mathrm{e} 3-9 \mathrm{aac}-00000 \mathrm{aacb} 360 \&$ acdnat $=1380202312$ f602cb1721cee2267384455760d74459>. Acesso em: 26 set. 2013.

PARK, J.T.; JOHNSON, M.J. A submicro determination of glucose Journal of Biological Chemistry, v.181, p.149-151, 1949.

RETORE, M. Caracterização da fibra de co-produtos agroindustriais e sua avaliação nutricional para coelhos em crescimento. 2009. 70p. Dissertação (Mestrado em Zootecnia). Curso de Pós-graduação em Zootecnia, Universidade Federal de Santa Maria.

RETORE, M. et al. Efeito da fibra de coprodutos agroindustriais e sua avaliação nutricional para coelhos. Arquivo Brasileiro de Medicina Veterinária e Zootecnia, v.62, n.5, p.1232-1240, 2010. Disponível em: <http://dx.doi.org/10.1590/S0102-09352010000500028>. Acesso em: 14 abr. 2013.

SCAPINELLO, C. et al. Fenos de leucena (Leucaena leucocephala e Leucaena leucocephala cv. 'Cunningham') para coelhos em crescimento: digestibilidade e desempenho. Acta Scientiarum. Animal Sciences, v.25, n.2, p.301-306, 2006. Disponível em: <http://periodicos.uem.br/ojs/index.php/ActaSciAnimSci/article/ viewArticle/2006>. Acesso em: 28 set. 2011. doi: 10.4025/ actascianimsci.v25i2.2006.

SILVA, D.J. Análise de alimentos: métodos químicos e biológicos. Viçosa: Universidade Federal de Viçosa, 1990. 166p.

TABORDA, C. et al. Manual de normas técnicas do biotério de experimentação animal. São Paulo: Departamento de Microbiologia do Instituto de Ciências Biomédicas da Universidade de São Paulo, 2004. 25p. Disponível em: <http://www.icb.usp.br/ bmm/arquivos/tecnicas_bio.pdf.>. Acesso em: 14 abr. 2013. 